СД-35.

\title{
ИДЕНТИФИКАЦИЯ БИОМАРКЕРОВ V-ГАЗОВ В БИОЖИДКОСТЯХ С ИСПОЛЬЗОВАНИЕМ ЖИДКОСТНОЙ ХРОМАТОМАСС-СПЕКТРОМЕТРИИ
}

Родин И.А., Браун А.В., Рыбальченко И.В., Байгильдиев Т.М.

Московский государственный университет имени М.В.Ломоносова, Москва, Россия avbraun@yandex.ru

DOI: 10.26902/ASFE-11_128

$\mathrm{V}$-газы являются высокотоксичными фосфорорганическими соединениями (ФОВ), которые, при попадании в живой организм, вызывают тяжелые отравления за счет ингибирования ацетилхолинэстеразы. В связи с этим их производство, накопление и применение запрещено Конвенцией по запрещению химического оружия, которая вступила в силу в 1997 году [1]. Однако, за последние два десятилетия отмечено применение токсичных химикатов в ходе военных конфликтов (Ирак, Сирия), также существует угроза использования ФОВ в террористических целях. Данные примеры показывают, что создание высокочувствительных аналитических подходов для установления фактов воздействия ФОВ на человека является актуальной задачей в рамках расследований возможного применения ФОВ.

В качестве объектов исследования выбраны биомаркеры соединений, относящихся к Vгазам - бутил S-2-диэтиламиноэтил метилфосфонотиолата (CVX) и изобутил S-2диэтиламиноэтил метилфосфонотиолата (VR). Поскольку данные соединения являются изомерами и имеют одинаковые пути трансформации в живом организме, существует сложность при обнаружении и идентификации их биомаркеров. В рамках данной работы исследовано масс-спектрометрическое поведение в варианте высокого разрешения двух биомаркеров, образующихся в плазме крови - тирозиновых аддуктов CVX и VR и двух маркеров - изобутил метилфосфоновой кислоты (IBMPA) и бутил метилфосфоновой кислоты (BMPA) - присутствующих в моче в случае попадания CVX и VR в живой организм. Удалось установить особенности масс-спектров фрагментации соответствующих изомеров и выбрать критерии для их надежной идентификации. Выбраны условия разделения тирозиновых аддуктов CVX и VR, а также IBMPA и BMPA, в варианте обращено-фазовой ВЭЖX-MC/MC, позволяющие проводить экспрессное обнаружение в человеческих плазме и моче.

Апробацию разработанных подходов проводили на экспонированных in vitro образцах плазмы крови человека и моче, искусственно зараженной IBMPA и BMPА. Предел обнаружения CVX и VR в человеческой плазме при детектировании в виде соответствующих тирозиновых аддуктов ограничен значением 5 нг/мл. В случае обнаружения IBMPA и ВМРА предел обнаружения составил 0.5 нг/мл.

\section{Сиисок литература}

1. Convention on the Prohibition of the Development, Production, Stockpiling and Use of Chemical Weapons and on their Destruction, Technical Secretariat of the Organisation for Prohibition of Chemical Weapons, The Hague, 1997 , accessible through internet http: / /www.opcw.org.

Исследование выполнено при финансовой поддержке РНФ в рамках научного проекта №19-13-00057. 